\title{
Older adults' experiences of participating in a study circle about aging and drugs
}

\author{
Karin Josefsson ${ }^{1^{*}}$, Johanna Gmeiner ${ }^{2}$, Jessica Karlsson ${ }^{2}$ \\ 1 University of Borås, Mälardalen University, School of Health, Care and Social Welfare, Eskilstuna, Sweden 2 Västmanland County \\ Council, Västerås, Sweden
}

\begin{abstract}
Background: Primary care physicians have a responsibility to inform older adults about the drugs and drug treatments they are prescribed so as to increase patients' compliance. However, this need is not always met. Use of a 'study circle' exercise may help older adults to obtain and increase their knowledge in a community setting, having the opportunity to share experiences with others in similar situations. The aim of this study was to describe older adults' experiences of taking part in a study circle about aging and drugs.

Methods: The study was designed to be descriptive with an inductive approach. Eleven older adults took part in focus group interviews in 2014, and the content of these interviews was analysed.

Results: Participants felt the design of the study circle exercise was good; having a syllabus to follow but at the same time allowing individuals' problems to be discussed. They described the leader of the study circle to be competent, with characteristics they appreciated. Participants found the study circle material informative, and it could be used as a reference for reflection. Participants' knowledge of natural and pathological aging was increased, as was their knowledge of drugs and their formulations. Participants felt more confident; they dared to ask questions, challenged new drugs, and proactively took action by seeking care when needed. The study circle format was recommended to other older adults. Participants suggested that in future the study circle could be extended and repeated, and that they could be provided with supplementary educational materials or exercises.

Conclusions: Use of a study circle about aging and drugs increased older adults' knowledge, and empowered them to ask questions and take an active part in their drug treatment. We believe that older adults have a desire to want to know more about the drugs they are prescribed, and want to be involved with their treatment, not simply passive recipients.
\end{abstract}

Citation: Josefsson K, Gmeiner J, Karlsson J (2015) Older adults' experiences of participating in a study circle about aging and drugs. Healthy Aging Research 4:28. doi:10.12715/har.2015.4.28

Received: February 3, 2015; Accepted: April 7, 2015; Published: April 25, 2015

Copyright: (C) 2015 Josefsson et al. This is an open access article distributed under the terms of the Creative Commons Attribution License, which permits unrestricted use, distribution, and reproduction in any medium, provided the original work is properly cited.

Competing interests: The authors have declared that no competing interests exist.

*Email: karin.josefsson@yahoo.se

\section{Introduction}

According to the World Health Organization (WHO) [1], drug therapy is currently the most comprehensive and decisive intervention in global health care. Treatment with pharmaceutical drugs is the most common medical intervention for older adults aged 65 years and more [2]. When used correctly it may maintain or improve a patient's quality of life.
However, aging may increase the risk of drug-related problems, including unsuitable choice of drugs, incorrect dosage, adverse drug reactions, drug-drug interactions, handling problems, inadequate or lack of efficacy, and compliance [2, 3, 4]. Nordin Olsson stressed that lower medication quality was associated with a lower quality of life [3]. Drug treatment among older adults is therefore a huge challenge for healthcare providers [3], not least because the rate at 
which the population is aging is increasing. It is estimated that by $2050,21 \%$ of the global population will be 60 years old or older [5].

Older adults often take ten or more drugs [6], which is associated with increased risk of increased emergency room visits and mortality. Among older adults, only $50 \%$ comply with their long-term drug treatment regimens [4]. This may be due to a lack of information about why and how their drugs are taken, and patients' ignorance about the implications of taking more than one drug simultaneously. Several studies have reported that older adults make their own decisions to change medicines or the duration of their use, and may even stop taking prescribed drugs altogether due to side effects, without seeking their physician's advice $[7,8,4,9]$.

A study circle is a form of group education involving content designs to address gaps in knowledge of a group of people with similar needs and interests [10]. The combination of study circles and implementation of a policy document can give the best outcomes in terms of increasing precision in preventative care [11]. Precision of care can be further increased if the study circle discussion has a specific focus. Participation in a study circle may facilitate a patient's own drug treatment and may help relatives to support and assist older adults. It may also lead to better, safer drug treatment [10]. Participation in a study circle may also increase participants' knowledge about their rights and responsibilities during contacts with their healthcare provider, as well as increase their self-confidence and preparation for these contacts [12].

Patient education can increase patients' knowledge and lead to their empowerment [13]. A challenge for healthcare is to evaluate the effects of patient participation on their feelings of empowerment, and their opinions about drug treatment [3]. The need for future research about older adults and drugs, and education, has been reported [14]. The aim of this study, therefore, is to contribute to research addressing this need by describing older adults' experiences of participating in a study circle on aging and drugs.

\section{Methods}

\section{Research design and ethics}

Healthy Aging Research | www.har-journal.com
The study was performed in Sweden during 2014. The study was designed to be descriptive and inductive [15] using focus group interviews [16]. Data were analysed using content analysis [17]. Ethical principles were followed for human medical research [18]. Participants gave their informed consent to participate in the study, after being provided with information about the study, including the fact that their participation was voluntary, and they could end the interview at any time without giving a reason. Participants were assured confidentiality and that results would be presented anonymously.

\section{The study circle}

A series of study circles entitled, "Eye on drugs" was conducted by the Swedish Pensioners' Association, in cooperation with the Pensioners' Association, and the Swedish pharmacy chain Farmaci [19]. The overall objective was to increase older adults' knowledge and understanding of drugs and their safe use, and that of their relatives. The study circle also aimed to increase participants' courage to empower them to ask questions. The study circle met seven times, for two hours at a time, and consisted of the same 7-10 participants in each group. The study circle leader was a pharmacist or registered nurse. All participants received the same materials before and during the meetings. The focus of each educational session was drugs, drug management, and drug treatment for common symptoms or diseases [19].

\section{Sample and data collection}

Criteria for participants' inclusion into a focus group for interview were: age of 65 years or older; member of the Swedish Pensioners' Association; participated in a study circle on aging and drugs; and able to speak and understand Swedish. An invitation to participate in the focus group for further study was sent to all $(n=$ 98) who participated in the study circle on aging and drugs within a geographic area of central Sweden. Fifteen older adults reported their interest to participate; therefore three focus groups of five older adults per group were scheduled to take place at the participants' domiciles. A letter was sent to each participant to inform them of the time and place for the interview. Three participants were unable
Josefsson et al. $2015 \mid \mathbf{4 : 2 8}$ 
participate on the chosen dates, and one did not show up to the first interview; therefore the total number of older adults participating in the interviews was 11 (Table 1).

Table 1. Characteristics of the focus groups and their participants

\begin{tabular}{llll}
\hline $\begin{array}{l}\text { Focus } \\
\text { group }\end{array}$ & $n$ & $\begin{array}{l}\text { Number } \\
\text { females }\end{array}$ & $\begin{array}{l}\text { Participants' } \\
\text { ages }\end{array}$ \\
\hline I & 3 & 3 & $81,82,85$ \\
II & 4 & 4 & $68,70,78,82$ \\
III & 4 & 2 & $71,71,95,97$ \\
\hline
\end{tabular}

Focus group interviews began with the opening question: A) "Can you talk about your experiences of participating in the study circle?" Follow-up questions were then asked, e.g.: B) "Was your experience good?" or C) " not so good?" D) "Can you talk about your experiences after the study circle?" E) "Can you talk about your experiences of drug treatment?" and F) "Health care contacts?" Supplementary questions were used as needed, including the following: a) Can you elaborate on that? b) Can you tell me more? c) In what way? d) Can you give examples? Participants were interviewed for 60-90 minutes. All interviews were recorded and transcribed verbatim.

\section{Data analysis}

Data were analysed by content analysis [17]. Interviews were first read in their entirety several times in order to get an overview of the content related to the study aim. Thereafter, meaningful units of text describing the older adults' experiences of participating in the study circle were identified and condensed. Next, these condensed units were abstracted to codes. The analysis went on to compare the content of the different codes to discern similarities and differences. Each code was provided with a number to discern whether recurrent subjects were from one or more participants. Codes with similar content were grouped together into 12 subcategories. The content of the sub-categories was compared and abstracted into gender categories. The content of the categories was compared. The authors continuously discussed the analysis process to achieve consensus. The analysis had an inductive approach, i.e. the categories were not determined in advance, but emerged through the analysis. Table 2 shows example of the content analysis process.

Table 2. Example of the content analysis process

\begin{tabular}{|c|c|c|c|c|}
\hline Meaningful unit of text & Condensed meaning unit & Code & Sub-category & Category \\
\hline $\begin{array}{l}\text {...and here it is important that } \\
\text { we are taking drugs with food } \\
\text { and perhaps the same time } \\
\text { each day and it was also } \\
\text { discussed. You get a certain } \\
\text { rhythm of it all. Yes one } \\
\text { thinks the more onit... }\end{array}$ & $\begin{array}{l}\text { Thinking more on time and } \\
\text { drugs associated with food }\end{array}$ & $\begin{array}{l}\text { Think more about } \\
\text { drugs routines }\end{array}$ & Drugs & Knowledge \\
\hline $\begin{array}{l}\text {... I thank not only and receive } \\
\text { drugs. Since I eat many drugs, } \\
\text { I ask if the drugs fit together } \\
\text { far. I had not thought about } \\
\text { that before, when I only } \\
\text { thanked and welcomed... }\end{array}$ & $\begin{array}{l}\text { Do not only receive drugs, ask } \\
\text { if the drugs fit, even though you } \\
\text { should not have to }\end{array}$ & To question & $\begin{array}{l}\text { Dared to ask and } \\
\text { to question }\end{array}$ & Empowerment \\
\hline
\end{tabular}




\section{Results}

\section{Study circle design and participants}

Participants expressed a wish to have weekly meetings, and requested that the meetings be longer than two hours since they felt stressed about running out of time. Apart from this, the participants' experience of the study circle design was good.

"Participant (P)1: "It's been good, very good..."

P3: "I think so too, it was fine, nothing to complain about..."

P2: "Mmm, they had designed it very well ..."

Participants felt that the group size (7-10) was just right to allow everyone to be heard. They felt that the study circle leader should be in control of the size of the group. Participants discussed deviation from the syllabus in order to discuss the problems they had, yet felt that, at times, the group was distracted by discussions about participants' own medical history; they thought the discussions would be more general rather than focused on individual's situations. Participants appreciated receiving information about the help and support that the municipality can provide for them at home.

Participants recounted that even though discussion topics were quite serious, the group often laughed, which lightened the atmosphere. This social interaction was thought to be a good way of meeting people instead of sitting at home alone. Participants were amused when others in the study circle demonstrated interest, engagement, and were asking questions. Participants enjoyed sharing their experiences and thought it was interesting to listen to others. It gave them insight into new substances and useful information for the future. However, the general consensus what that too much time was spent discussing individuals' diseases and ailments; the study circle leader should have steered the discussion back to the topic of "Aging and drugs".

P3: "...often someone will say something, and someone else has the same problem, so they will talk about that. Often, you two have the same thing, so you will take up that subject..."

P1: “... but it's not a problem as now we've prepared ourselves..."

\section{The study circle leader}

\section{Competence}

Older adults participating in the study circle had nothing but positive comments to make about the study circle leader. They felt it was important for the study circle leader to be a registered nurse or pharmacist, since they were considered competent. The study circle leader provided answers to many of the participants' questions and had insight into various areas, for example, a registered nurse could provide answers to questions about the help older adults could get from the municipality, not just about drugs. Pharmacists could answer many specific questions about drugs.

P6 “...the study circle leader was competent..."

P4, P5: "Yes..."

P7: "Ours was also very competent. She knew what she was talking about. She was a pharmacist, though she is retired now..."

P4: "Mmm. Yes, the study leader here was a nurse and she also knew about drugs. She was also aware of some different ways, like you said, to get help in the municipality..."

Participants reported that they engaged in a dialogue with the study circle leader, who adapted his or her responses so that participants could understand. The study circle leader also encouraged participants to initiate discussion by asking them questions, or asking for thoughts on a particular topic.

\section{Personality}

The study circle leader's appearance and personality was important to participants, since this demonstrated the leader's openness, humility and encouragement. There was a pleasant atmosphere, which encouraged participants to speak out and ask questions. The study circle leader's positivity was important.

P9: "...those who are leaders ought not to lead 'too much'. The leader we had was able to guide the conversation, but had no superior teaching style they were quite humble, somehow..."

P1:"...Well, so was our leader. It is important..." 


\section{Reading materials}

\section{Usability}

The usability of the reading materials provided was an important part of the study circle format. Participants carefully processed the reading materials during the study circle meeting, and were able to review it at home, in advance of the meetings, so as to be prepared to discuss in the group and raise questions. Participants described the reading materials as 'welldefined' and 'easy to read with interesting content'. They thought the materials were useful for future reference, in particular the advice on questions to ask during face-to-face physician visits. The reading materials were helpful for those who had problems keeping up with the discussions during the study circle, or who were not present at the study circle since they could go back and read it later.

P9: “...the discussions became quite lively, but one or two people did not get involved much... maybe they were unaccustomed to speaking in public...but they have all the reading materials to read later..."

P11: "Yes exactly..."

P9: "They can take the materials and revisit the topics..."

\section{Informativeness}

The reading materials provided good depth of information about drugs and diseases, as well as preventive information on these topics.

P2: “...here you can read about...prevention of cardiovascular diseases, for example...it is about high blood pressure..."

P1: "There was a lot of information ..."

Participants described the reading materials as 'informative,' emphasizing that they had increased their awareness of the topic and caused them to start to think more. After the study circle, participants pondered over their physicians' knowledge of inappropriate drugs for older adults.

\section{Knowledge}

Natural and pathological aging
Participants felt that the study circle had increased the knowledge they already had about the natural aging process. Participants felt the experience was interesting, positive, and had increased their awareness of issues associated with aging and drugs.

P4 "...I was told that the body and bodily functions may not work as well as when you were young ...I know nothing about my kidneys and liver and stuff like that, but I was told about the kidneys during the study circle, and the dosages and medications it has to cope with..."

P7: "Oh yes, the kidneys are very sensitive..."

Participants' knowledge about diseases, symptoms, and the importance of seeking health care was increased thanks to the study circle. This meant they began to think about risks, and to take action against those risks, including starting to eat more healthily and take part in exercise. They demonstrated an ongoing need for general information about what is normal and abnormal. They recounted that they had started to talk about their own diseases.

\section{Drugs}

After having participated in the study circle, participants said they had gained new knowledge about drugs and which are inappropriate for older adults to take. They had increased awareness of dosages and drug regimens, and on interactions between drugs and diet, health foods and alcohol.

P2: "...we discussed whether we were taking medications with food, or perhaps at the same time each day. It makes you think about the rhythm of it all..."

The study circle increased participants' interest of medicines in the media. They also learned about the importance of having a physician with primary responsibility for all drugs. Although some felt the topic was still difficult to understand, participants valued the discussion on generic drugs and thought they would feel more confident in demanding the original drug if they wanted it, as opposed to the generic version, despite the increased cost. Participants felt that the small print on pharmaceutical leaflets and labels was difficult to read and complicated to understand. 


\section{Empowerment}

Participants explained that the study circle motivated and empowered them to question new medications, to require explanations from their physicians as to why a particular drug was needed, and to say no to the physician if they did not feel comfortable with a particular drug. Participants described that they became more attentive to their treatments, and were not afraid to ask if the new drug was compatible with other medications.

P6: "...I take many drugs now, but I had never thought to ask if they were safe to take with others..."

The study circle provided tips on how to prepare for physician's visits by writing down their thoughts and questions in advance. Some people already did this before the study circle, but said they paid more attention to their lists now. Preparing for a doctor's visit made it easier for them to be brave enough to ask questions.

\section{Actions}

Participants related that they now felt more responsible to keep up to date with their own situations, and to actively seek care. Some mentioned that they had spoken to their children about the medications, and said they would review the drugs and speak up if they felt they were unable to administer them by themselves. The study circle format seemed to increase participants' awareness of the rights they have, as older adults, in the management of their own health care, and were motivated to take action when needed. Some participants had changed their healthcare center after the study circle.

P6 "...the study group leader advised that we should call our doctors and interview them to ask if the medicines they prescribed were compatible with each other. When I spoke with my doctor, something had happened to her at lunchtime and she said she would be visited by police officers. She began by asking, "aren't you afraid of the police?" "No, why would I be?" "The cops will be here soon," she said. So it was the police who occupied the doctor's time with me, and the only thing I asked was whether my medications were compatible with each other. I was taken aback when the doctor said, "Of course, otherwise I wouldn't have written the prescription ..."

P7: "Oops!"

P6: “...thank you, I said, and I went out ..."

\section{Evaluation}

\section{Future request and recommendation}

Participants asked if the study circle exercise could be expanded to provide information about the help they were entitled to receive from the municipality, for example security alarms, social care, and transportation services, as well as further opportunities to discuss physician contact. Participants stressed that repetition of the study circle would be desirable to allow them to retain the knowledge they had learned for longer.

P9: “...something I would wish for is repetition..."

P11: "Yes..."

P9: “...then it would sit much better..."

P11: "Yes, exactly..."

P9: "Yes..."

P10: “...Yes, you're right about that..."

Participants wanted to meet more often and over a longer period of time, since they believed that would help them to more easily remember what they learned. They suggested that the meetings should start with a recap of the previous meeting, and a supplementary course to help deepen their knowledge. Participants recommended that a study circle should have more than one leader; perhaps both a registered nurse and a pharmacist to complement each other's knowledge. They also suggested that other professionals could be invited to lead, for example municipal staff.

Participants felt that the study circle format was good, meaningful and instructive. They wanted other study circles of the same kind in the future. They expressed a need for study circles, and recommended the format to other retirees and associations.

P6 “...I really would recommend all older adults to participate in this kind of study circle, because I think everyone needs it. Whether you take prescribed drugs or not, it's better to learn..." (All agreed.) 


\section{Discussion}

Though it may be argued that this study is limited by the lack of data collected regarding participants' education, Barski-Carrow [20] showed that the study circle exercise achieved its educational objectives despite participants' differing education levels. The results cannot be generalized to a wider sample. However, the results may reflect the experiences of older adults in similar conditions, have an important value, and are relevant to clinical practice.

Participants' interactions in the study circle were affected by experiences of their ownb medical conditions, and their level of participation in the exercise. They generally had a positive experience, explaining that they felt the study circle gave them greater insight that would be useful in the future; this is in line with findings made in previous research [12, 20]. A drawback of the study circle was that some participants tended to want to talk about their own illnesses and experiences with drug treatments; this meant that not all participants were given time to talk.

Analysis of participants' comments revealed that they felt the study circle leader played an important role in the exercise. They felt it was important that the leader was credible and qualified, e.g. a pharmacist or a registered nurse responsible for prescribing drugs in primary care. Many of the participants' questions about drugs and medications were answered satisfactorily. Previous research has shown that older adults often feel they have been given incomplete information about their medications [21]; given that the Swedish Health Care Act stresses that patients should receive personalized information about their treatment.

Encouragement can be linked to the concept of empowerment [22], which in turn can promote participation - in this study the study circle leader's personality and humility was certainly found to positively influence the participants' interactions

Participants praised the reading materials provided for use before, during and after the study circle. They found it to be full of useful, informative content that could be used as a reference book at home, and the advice contained within it also helped them to prepare for physicians' visits. Previous research has shown that older adults used alternative sources of information and found it comforting to revisit information in order to learn it [21]. We believe that use of the study circle reading materials makes older adults feel secure, and can contribute to their participation and empowerment [22]. For reading materials to be most effective however, it is important that they are updated in light of new drugs.

As has been found in previous research [12], the participants in our study found that their knowledge of physical aging, diseases and symptoms was increased, and the knowledge they already had was reinforced following the study circle exercise. This new knowledge meant that participants realized their risk of health complications, and therefore started to take steps to eat more healthily, take exercise, and seek care when needed. We consider this finding to be significant both for the participants themselves, and for those administering their care, since actions that are in line with the preventative work of primary care providers can also contribute to increased patient participation and empowerment $[13,22]$.

Previous research has shown that older adults often lack knowledge about the consequences of refraining from taking a drug, in terms of side effects and toxic risks [9]. We are therefore encouraged that the participants in this study felt their knowledge of drugs, dosage and procedures had been increased, since this suggests that adherence to a treatment regimen may be increased [4]. Use of the study circle also improved participants' knowledge and understanding of physicians' pharmaceutical reviews of drug treatments. It is a positive finding that the participants had increased awareness of their rights, which may lead to greater participation and feelings of empowerment [22].

Analysis of participants' comments revealed that they felt they should be prescribed original, branded drugs rather than generic alternatives because they felt confused by generic alternatives and believed the branded drug to be more effective. Having participated in the study circle, some older adults said they would stand firm and ensure they received original drugs, despite the increased cost [21], while others understood that generics have the same active ingredients but are cheaper [21]. We believe that health care providers should keep this in mind and support older adults in their preference for the original 
branded drug. We feel it is a positive finding that, after participating in a study circle, older adults feel more empowered to make decisions about their drug therapy [22].

Our study revealed participants felt motivated by taking part in the study circle, and were given the confidence to dare to ask questions about new drug treatments. This result is consistent with previous research [12], which described an increase in selfconfidence in study circle participants. Older adults were also motivated to keep abreast of their own situations, and to actively seek care when needed. Encouraging older to adults to participate in their healthcare is empowering [22]; we believe that empowerment and greater understanding of drug treatments can reduce the risk of treatment errors, lead to increased security and better adherence [4].

The study circle gave participants tips on how to prepare for physician visits, including writing a list of questions to ask the doctor in advance. We feel this is a positive result in line with previous research [12], which also reported that study circle participants were better prepared for contact with their physician. We believe that a well-prepared patient is an involved, empowered patient, whose doctor visits are more effective [22]. This can benefit both the patient and the caregiver.

Participants argued that the study circle was worthwhile, and even recommended it to their peers even for those not taking drug treatments. Previous research has also shown that participants recommended others to attend a study circles [23]. We believe that use of the study circle exercise is an advantageous form of preventive education for use in a variety of care settings.

\section{Conclusions}

This study provides evidence to suggest that use of the study circle format to educate older adults about the effects of aging and drugs was useful for increasing participants' knowledge. It also seemed to empower participants to ask questions and become more actively involved in their drug treatment. This study also demonstrates that older adults do not wish to be passive recipients of drug treatment, but have an interest in knowing more about the drugs they are prescribed.

\section{Acknowledgments}

We are grateful to Leena Eklund and Lena Olofsson who were involved in the implementation of the study circles and made it easier for us to conduct the study and to all participants in this study. We thank the team at Healthy Aging Research for their assistance with proofreading the manuscript.

\section{References}

1. World Health Organization. Medicines: rational use of medicines. Fact sheet no. 338 [Accessed 201504 22]. World Health Organization; 2010. Available from: http://www.wiredhealthresources.net/resources/NA/WH O-FS_MedicinesRationalUse.pdf

2. Hanlon JT, Schmader KE, Semla TP. Update of studies on drug-related problems in older adults. J Am Geriatr Soc. 2013;61:1365-8.

3. Nordin Olsson I. Rational drug treatment in the elderly. To treat or not to treat? [dissertation]. Örebro: Örebro University; 2012.

4. Fastbom J. Äldre personer och läkemedel. Stockholm: Liber; 2006. Swedish.

5. UN.org [Internet]. World population ageing: 1950-2050 [cited 2015 Jan 31]. United Nations; 2002. Available from:http://www.un.org/esa/population/publications/wor ldageing19502050/

6. National Board of Health. Äldre med regelbunden medicinering - Antalet läkemedel som riskmarkör. Stockholm: National Board of Health; 2012. Swedish.

7. Norris PT. It's just a routine. A qualitative study of medicine-taking amongst older people in New Zealand. Pharm World Sci. 2010;32:154-61.

8. Gordon K, Smith F, Dhillon S. Effective chronic disease management: patients' perspectives on medicationrelated problems. Patient Educ Couns. 2007;65:407-15.

9. Barat I, Andreasen F, Damsgaard EM. Drug therapy in the elderly: what doctors believe and patients actually do. Brit J Clin Pharmacol. 2001;51:615-22.

10. Nestor FoU-center. Må bra - med eller utan läkemedel: Ett studiecirkelmaterial för äldre och deras närstående. Haninge: EO Grafiska; 2012. Swedish.

11. Westergren A, Axelsson C, Lilja-Andersson $P$, Lindholm C, Petersson K, Ulander K. Study circles improve the precision in nutritional care in special accommodations. Food Nutr Res. 2009;23:53. 
12. Sönnerberg E, Edgren L, Welin L. The patient's role in a changing world - results of a study circle for diabetes patients. Nordic J Nurs Res. 2001;21:38-41.

13. Rasjö Wrååk G, Törnkvist L, Hasselström J, Wändell PE, Josefsson K. Nurse-led empowerment strategies for patients with hypertension: a questionnaire survey. Int Nurs Rev. Forthcoming 2015.

14. Keijsers CJPW, van Hensbergen L, Jacobs L, Brouwers JR, de Wildt DJ, ten Cate OT, et al. Geriatric pharmacology and pharmacotherapy education for health professionals and students: a systematic review. Brit J Clin Pharmacol. 2012;74:762-73.

15. Polit D, Beck C. Nursing research: generating and assessing evidence for nursing practice. Philadelphia: Lippincott Williams \& Wilkins; 2011.

16. Krueger RA, Casey MA. Focus groups: A practical guide for applied research. 4th ed. Thousand Oaks, CA: Sage; 2009.

17. Graneheim UH, Lundman B. Qualitative content analysis in nursing research: concepts, procedures and measures to achieve trustworthiness. Nurse Educ Today. 2004;24:105-12.

18. World Medical Association. World Medical Association declaration of Helsinki. Ethical principles for medical research involving human subjects. Bull World Health Organ. 2013;310:2191-4.

19. Melander A, Nilsson L. Kloka rättigheter som ger dig en bättre läkemedelsbehandling. Stockholm: Swedish Pensioners' Association, Pensioners' Association, and Pharmacy Farmaci; 2013. Swedish.

20. Barski-Carrow B. Using study circles in the workplace as an educational method of facilitating readjustment after a traumatic life experience. Death Stud. 2000;24:421-39.

21. Modig S, Kristensson J, Troein M, Brorsson A, Midlöv P. Frail elderly patients' experience of information on medication. A qualitative study. BMC Geriatr. 2012;12:1-10

22. Fumagalli LP, Radaelli G, Lettieri E, Bertele P, Masella C. Patient empowerment and its neighbours: clarifying the boundaries and their mutual relationships. Health Policy. 2015;119(3):384-94.

23. Lantblom AE, Lang C, Flensner G. The study circle as a tool in multiple sclerosis patient education in Sweden. Patient Prefer Adherence. 2008;2:225-32. 